\title{
LEON WALRAS EN LA HISTORIOGRAFIA DEL PENSAMIENTO ECONOMICO: MATERIALES PARA UNA REINTERPRETACION
}

JULIO SEGURA

Fundación Empresa Pública

\section{INTRODUCCION}

La obra de Léon Walras (1834-1910) es, en su mayoría, casi desconocida, incluso por el público especializado. La escasa lectura directa de Walras ha dado lugar a la transmisión de una imagen incompleta $y$, lo que es peor, deformada de uno de los economistas más importantes de la historia del pensamiento económico.

Existen varias razones que explican el porqué la escasa lectura de Walras. En primer lugar, su obra, muy extensa y dispersa, está escrita en un estilo farragoso y reiterativo que no sólo la convierte en poco atractiva desde el punto de vista literario, sino que, además, la hace a veces poco inteligible. En segundo lugar, editada en francés en una época en que los idiomas dominantes en economía eran el inglés y el alemán, y publicada en revistas y boletines científicos de escasa circulación, la obra de Walras fue, incluso en su tiempo, de muy limitada difusión. $Y$, ya en nuestros días, hasta la soberbia edición anotada y cotejada de los Eléments d'économie politique pure (EEPP), publicada por Jaffé en 1954, no se ha dispuesto de parte de su obra en inglés. Pero, para entonces, el análisis de equilibrio general había adquirido un grado de autonomía dentro del campo de la teoría económica, y se había formalizado lo suficiente, como para hacer que la lectura de Walras fuera improductiva a medio - $y$, quizá, incluso a largo- plazo, dadas las normas internas del mundo académico.

En tercer lugar, el peculiar uso que Walras hizo del instrumental matemático dificulta la lectura de sus aportaciones analíticas para una profesión más habituada a una teoría walrasiana divulgada por G. Cassel (1918), F. Zeuthen (1942, cap. 11) o Bowley (1924), o formalizada en los trabajos pioneros de G. Debreu y K. A. Arrow a partir de la década de los años cincuenta.

Por último, buena parte de su elaboración analítica es de carácter cíclico $y$ acumulativo, de forma que no es infrecuente encontrar juntos, en versiones 
finales de sus trabajos - $-v$. gr., $4 .^{\text {a }}$ ed. definitiva de los EEPP_, argumentos pertenecientes a etapas distintas de su proceso de construcción teórica que, en algunos casos, resultan incompatibles. Dato significativo de la complejidad de la obra teórica pura de Walras es el hecho de que autores como J. R. Hicks, A. W. Marget, M. Morishima, D. Patinkin, G. J. Stigler o K. Wicksell -que consta sí han leído a Walras- no difieran sólo en su interpretación, sino incluso en lo que creen que dijo.

Las razones apuntadas explican, al menos parcialmente, la reducida lectura de la obra de Walras, pero en modo alguno justifican ni su escasa importancia en vida, ni la visión deformada con que aquélla ha quedado plasmada en las obras más importantes de historia del pensamiento económico. Lo primero, porque ningún economista del s. xix fue autor de grandes éxitos editoriales, y para que sus doctrinas ejercieran influencia resultaba suficiente que accedieran a un reducido núcleo de profesionales, al que es comprobable alcanzó la obra analítica de Walras. Lo segundo, porque las dificultades de acceso, lectura e interpretación de una obra no disculpan un juicio incorrecto por parte de historiadores del pensamiento.

Por todo ello creo que puede resultar útil analizar por separado dos aspectos distintos del fenómeno señalado. El primero, la escasa importancia que Walras tuvo en vida como economista. El segundo, el hecho de que, incluso una vez reconocida universalmente su importancia, la bistoriografía del pensamiento económico ba proporcionado una visión reduccionista y sesgada de la obra de Walras.

Este artículo trata de explicar el porqué de este doble fenómeno y de presentar una visión más integral de la obra de Walras y de las relaciones existentes entre las distintas partes de la misma. En el epígrafe 2 se explican en forma sintética los motivos por los que las doctrinas walrasianas tuvieron escaso éxito en su época. El epígrafe 3 da cuenta documentada de la visión reduccionista de la obra de Walras, dominante en la historiografía del pensamiento económico. Por último, en el epígrafe 4 se ofrece una interpretación de la obra de Walras que permite entender la forma en que se gestó, y de la que emerge un autor discutible, pero mucho más sugerente que el mayoritariamente conocido ${ }^{1}$.

1 Este artículo se basa en mi trabajo introductorio a la versión anotada española de los EEPP, titulado «La obra de Walras al cabo de un siglow (Segura, 1987, pp. 20-55). Se han eliminado del mismo las referencias a la vida de Walras, que pueden consultarse en Jaffé (1965, CRP, vol. I, pp. 1-36), en la traducción al español de esta última referencia (Segura, 1974) o en Segura (1987, Apéndice I, «Sinopsis de la vida de Leon Walrasw, pp. 56-69). El objetivo de dicho trabajo era, por una parte, explicar el porqué de la visión más difundida de la obra de Walras y, por otra, presentar una síntesis descriptiva y valorativa de la misma. Aquí el interés se centra más en la descripción de cuál es la visión de la obra de Walras, tal y como ha llegado a nuestros días, y en la 


\section{WALRAS: UN AUTOR POCO INFLUYENTE EN SU EPOCA}

Existen tres razones fundamentales que, en mi opinión, explican el escaso eco de la obra de Walras comentada en $\$ 1$. En primer lugar, la imposibilidad que, por distintos motivos, tuvo para penetrar en los núcleos dominantes de la economía en su tiempo - la Inglaterra de A. Marshall, el historicismo alemán y el mundo austríaco de E. Böhm-Bawerk-, lo que limitó de forma crucial la difusión real de su obra analítica. En segundo lugar, la carencia de apoyo gubernamental o institucional alguno hizo que sus numerosas aportaciones al campo de la economía aplicada nunca fueron objeto de debate público, no influyendo, por tanto, lo más mínimo ni en las decisiones ni en reformas económicas de su tiempo, por lo que sus propuestas nunca superaron las fronteras del mundo estrictamente académico. Por último, sus proclividades socialistas, su dura crítica a las instituciones sociales y económicas de la época y sus propuestas como reformador radical en el ámbito de la economía social le cerraton el acceso a los círculos de influencia; al mismo tiempo que sus críticas a muchas concepciones socialistas clásicas hicieron que dichas propuestas carecieran de eco en la propia izquierda. Examinemos estas tres razones.

Lector atento e inteligente de los clásicos ingleses, Walras obtiene empero su inspiración de la tradición francesa: J. B. Say en la teoría del valor basada en la escasez - completada por su padre Auguste, más que notable economista-, A. Cournot en el uso del método matemático, y los fisiócratas en su justificación de que el Estado debe financiarse por la renta de la tierra. Y no se trata tan sólo de que las raíces de Walras y sus contemporáneos ingleses fuesen distintas, sino de que su posición respecto a los clásicos británicos es muy crítica (L. Walras, 1926, lecciones 38-40).

Resulta significativo que, de entre los codescubridores de la teoría de la utilidad, sólo Walras se mostrara crítico respecto a la escuela clásica. Así, por ejemplo, Jevons fue ricardiano en todo excepto en la teoría del intercambio puro de mercancías, y Marshall no se planteó problemas por defender en forma simultánea la teoría del valor basado en la utilidad y la determinación del precio de los productos por los costes de producción - algo poco sorprendente habida cuenta de la paradigmática capacidad del inglés para hacer compatibles planteamientos antagónicos.

La posición crítica global proviene del hecho de que, para Walras -al contrario que para Jevons, Menger, Gossen o Marshall-, la teoría de la utilidad constituye el punto de partida del análisis del equilibrio general, y no

interpretación de la misma. Ambos trabajos se complementan, pero tienen una parte coincidente que, en lo fundamental, se refiere al epígrafe 2 de éste. Agradezco la atenta lectura de una primera versión del trabajo realizada por Francisco Comín, que me permitió introducir mejoras de comprensión en el texto. 
sólo una solución al problema del intercambio o de la demanda. Es, por tanto, una consecuencia lógica de haberse planteado como objetivo el estudio del sistema competitivo en su integridad.

Partiendo de estas posiciones, no puede extrañar que el acceso de Walras al mundo académico inglés fuera limitado y muy trabajoso, pese a que siempre tuviera conciencia de la importancia de penetrar en el mismo. Las únicas relaciones satisfactorias fueron las mantenidas con Jevons, pero se truncaron con la prematura muerte de éste. Su trato con Marshall, que pocas veces pasó de meros acuses de recibo o breves notas de desacuerdo y desinterés por parte del inglés, empeora tras un comentario despectivo de éste respecto a la originalidad del concepto de estabilidad en el caso de equilibrio múltiple. La opinión de Marshall sobre Walras nunca pasó, en el mejor de los casos, de una distante displicencia respecto a un autor preocupado por temas abstractos y que, cuando se ocupaba de problemas reales, lo hacía en forma ingeniosa, pero impracticable.

Las relaciones con F. Y. Edgeworth son todavía peores, entre otras razones, porque se plantean en ellas problemas teóricos dentro del mismo campo -algo que no sucede en el caso de Marshall-, y transmiten una clara sensación de superioridad recíproca. Tras la publicación por parte del inglés de una crítica a la 2." edición de los EEPP (Edgeworth, 1889), que, junto a aciertos, presenta importantes fallos de comprensión de piezas centrales del análisis de equilibrio general, Walras manifiesta opiniones sobre Edgeworth que van desde calificarle de «atolondrado» hasta considerarle «un camelista capaz de desacreditar el nuevo método [matemático]» (CRP, carta 1000). Por su parte, Edgeworth, en su papel de editor del Economic Journal, llegó a rechazar la publicación de un trabajo de Barone, decisión injustificable dada la calidad del original y sólo achacable a que en el mismo se mantenían posiciones favorables a Walras y contrarias a P. H. Wicksteed sobre el tema de la teoría de la productividad marginal aplicada a la distribución ${ }^{2}$.

Por último, su relación con.Wicksteed comienza siendo excelente, como muestran tanto las precisas y valiosas sugerencias del británico al texto de la 2. ${ }^{2}$ edición de los EEPP (CRP, carta 875) como la opinión de Walras, que pensaba en 1889 que Wicksteed «es más independiente [que Edgeworth y Marshall] y puede que sea mi hombre en Inglaterra» (CRP, carta 925). Posteriormente comienzan a manifestarse divergencias entre ambos, cuyo contenido objetivo - la teoría de la productividad marginal aplicada a la distribución- en modo alguno justifica el apéndice III de la 3. edición de los EEPP,

2 Una detallada cuenta del texto de Barone - que se conserva gracias a la traducción realizada por Walras para uso personal-, y su significado en la polémica sobre el principio de la productividad marginal, se encuentra en Jaffé (1964). 
que es una acusación de plagio y que, con buen criterio, Walras eliminó en la $4 .^{2}$ edición de 1900 . Pero para entonces la relación ya se había cortado.

El resultado de este difícil contacto con los economistas ingleses más relevantes en la época es que Walras nunca tuvo «su hombre en Inglaterra», y esto limitó de forma sustancial tanto la difusión como la valoración de su obra en vida ${ }^{3}$.

Las relaciones de Walras con el historicismo y el socialismo de cátedra alemanes requieren pocas palabras. Nuestro autor nunca intentó penetrar en ese poderoso mundo académico, no tanto porque en él se hiciera economía institucional o histórica, sino porque, en su opinión, se confundían los distintos planos del análisis económico y no se justificaban en forma científica las conclusiones, ni siquiera en los casos en que eran correctas. En concreto, Walras vertió fuertes críticas contra «la confusión entre ciencia y práctica», característica, según él, del pensamiento alemán de la época, al que llegó, incluso, a acusar de esterilizar con ello el magnífico diseño de su sistema educativo superior (L. Walras, 1879 a). Sus relaciones con otros economistas ejercientes en Alemania - por ejemplo, L. Bortkiewicz- fueron excelentes, pero poco útiles, dada la posición académica de los mismos.

La vinculación de Walras con la escuela austríaca se diferencia de las anteriores, tanto en la forma como en el fondo, pero es igualmente inútil en lo tocante a la difusión de su obra. La similitud, a efectos analíticos, entre los conceptos de Grenznutzen austríaco y rareté walrasiana ${ }^{4}$ y la común defensa de la teoría del valor basada en la utilidad son coincidencias importantes. Walras consideraba a los austríacos superiores, incluso, a Jevons por haber ampliado su análisis al campo de la producción a través de los conceptos de producto y productividad (L. Walras, 1926, Prólogo). Estas coincidencias dieron lugar a una cordial relación con Menger, a quien siempre reconoció la prioridad en la formulación del concepto de utilidad (L. Walras, 1926, \$164), y a buenas relaciones con Böhm-Bawerk, de quien recibió comentarios útiles sobre sus EEPP en, por ejemplo, el tema del equilibrio con curvas de utilidad discontinua (v. gr., CRP, carta 782). Sin embargo, las diferencias entre la concepción walrasiana y austríaca de las teorías de la formación de capital y de la determinación del tipo de interés eran abismales y decisivas para que BöhmBawerk considerara incorrecta la obra del francés en el tema objeto de su atención preferente. Por último, las divergencias respecto a la necesidad de

${ }^{3}$ El lector interesado en una descripción más detallada y documentada de las relaciones de Walras con Jevons, Marshall, Edgeworth y Wicksteed puede consultar Segura (1987, pp. 2428).

4 Ámbos conceptos no son, sin embargo, idénticos, como ocurre con el final degree of utility de Jevons y la rareté. Un análisis de las diferencias entre ambos se encuentra en Jaffé (1954, n. 9, pp. 506-507; en la versión española, n. 7, pp. 261-263). 
utilizar el método matemático también les separaban y dificultaban su mutua comprensión (L. Walras, 1926, \$164).

En resumen, y con independencia de la mayor o menor cordialidad de sus relaciones personales, Walras vio cerrado el acceso, por causas distintas, pero igualmente determinantes, a los dos focos principales de elaboración e influencia teóricas de su tiempo.

Por último, sus relaciones con el resto del mundo académico - si se ex. ceptúa el francés- fueron en general buenas, pero no muy útiles, ya que poco podían ayudar a la difusión de su obra dentro de Inglaterra o Austria; y su muy positiva vinculación con los estadounidenses I. Fisher y H. L. Moore le supuso un importante reconocimiento moral, pero nada más.

El único núcleo teórico de cierto peso donde sus opiniones encontraron eco fue el italiano. Su relación con E. Barone fue intensa, satisfactoria y sig. nificativa, desde el punto de vista técnico, pero éste no fue reconocido como un economista de primera magnitud hasta mucho después de su muerte. Las relaciones con la estrella del grupo, V. Pareto, requieren un comentario más detallado.

Pareto trabó conocimiento con Walras por medio de M. Pantaleoni, en 1891, con el claro objetivo de sucederle en la cátedra, cuando ya era pública la enfermedad de Walras. En efecto, un año después, Pantaleoni sugirió a Walras la idea de que Pareto fuera su sucesor, iniciativa que aquél asumió como suya de forma desinteresada. Pareto trató con enorme deferencia formal a Walras, haciéndole observaciones teóricas atentas, bien que marginales, en algunos puntos. Pero la simpatía que tenía por su predecesor era mínima, considerando absurdas todas sus conclusiones en materia de economía aplicada y social (véase próximo epígrafe). Algo que cabía esperar dada la ideología, inicialmente ultraliberal y más tarde autoritaria, del italiano. Incluso, desde el punto de vista teórico, las divergencias entre ambos autores son mayores que las imaginables cuando se habla de Pareto como continuador del análisis de equilibrio general walrasiano (véase Pareto, 1902, y CRP, carta 1502, n. 11). En consecuencia, pese a haber fundado la llamada Escuela de Lausanne, ésta se articuló mucho más en beneficio de Pareto que de nuestro autor.

El segundo motivo señalado como causante del escaso éxito en vida de la obra de Walras es las condiciones de aislamiento personal y la carencia de apoyo institucional en que desarrolló su trabajo. Impedida la enseñanza en Francia por su enfrentamiento con la Academia y las constantes y acerbas críticas a los profesores de la época y al sistema universitario de la Restauración conservadora, optó en 1870 por ir a Lausanne, en condiciones incluso precarias por su provisionalidad, para ejercer su magisterio con alumnos de derecho, de entre los cuales, como era de esperar, no surgió un solo economis- 
ta de peso. Las veces que intentó ser representante francés o suizo en conferencias internacionales - sobre temas monetarios y educativos- vio rechazada su oferta, y las escasas veces que ejerció como asesor o consultor en materias de política económica —en temas monetarios, fiscales y de regulación de la propiedad intelectual - fue para el gobierno de un país poco importante en el concierto internacional como el suizo, y adoptando posiciones hipercríticas expresadas en forma tan poco diplomática como habitual en él ${ }^{3}$.

El tercer motivo aquí aducido para explicar el fracaso de Walras en vida es su posición política. Ahora el punto central es su creencia de que las tierras son propiedad del Estado — que será discutida en el epígrafe 4-, por lo que fue acusado con frecuencia de socialista y estuvo a punto de costarle su puesto en la Academia de Lausanne ${ }^{6}$. J. A. Schumpeter le calificó de «semisocialista» (1954, p. 888) y Jaffé se ha preguntado con ironía si cabe siquiera llamarle «hemi-semi-demi» socialista $(1975$, p. 821). El tema de si Walras fue o no realmente socialista tiene poca importancia en este contexto, porque para que sea un factor explicativo de su aislamiento es suficiente que fuera considerado como tal por sus contemporáneos influyentes, $y$ asi lo fue ${ }^{7}$ : él mismo se calificó de socialista (v. gr., CRP, carta 1262), aunque lo matizara de forma peculiar, distanciándose tanto del socialismo ortodoxo como del de cátedra.

Walras mantuvo una posición que calificó con optimismo de síntesis entre el socialismo y el liberalismo: la articulación política de la sociedad definitoria del liberalismo que emergió de la Revolución de 1789 era la mejor, pero la experiencia restauradora francesa le llevó al convencimiento de que dicho sistema se había mostrado incapaz de dar satisfacción a las demandas de cambios económicos y sociales que estallaron en la Revolución de 1848. Desde una perspectiva científica, Walras consideraba al socialismo como una forma organizativa superior al liberalismo (L. Walras, 1866 a y $b$ ). Incluso opinaba que el comunismo estaba en lo cierto cuando exigía la igualdad de condiciones para todas las personas, siendo el liberalismo correcto al admitir la desigualdad en las posiciones finales de cada individuo en la sociedad, siempre que éstas fueran el resultado de diferencias en las decisiones libremente tomadas por cada persona partiendo de una situación de igualdad originaria (L. Walras, 1896 a). Es claro que no creía que la sociedad de su época garantizara la igualdad de oportunidades, y por ello la consideraba científicamente imperfecta, aunque

s Para un análisis de los fracasos de Walras como asesor y de las posiciones mantenidas cuando actuó como tal, véase Jaffé (1975). A los cinco casos tratados en este trabajo habría que añadir uno de 1880 sobre el proyecto de ley suizo de la propiedad intelectual y el recogido en $L$. Walras (1889).

- Es significativa en este aspecto la observación de la minoría ( 3 votos de 7) añadida al Acta de nombramiento por un año de profesor de Economía Política de la Academia de Lausanne (Oulès, 1950, pp. 119-122; versión española en Segura, 1987, pp. 104-105).

7 Incluso en forma impresa. Como muestra, véase, por ejemplo, Péguy (1897). 
en ningún momento mantuvo posiciones igualitaristas. Por si pudiera caber alguna duda respecto al tipo de socialismo profesado por Walras, la idea de revolución social que defendía basta para alejar toda sospecha subversiva ${ }^{8}$.

$\mathrm{E}_{\mathrm{n}}$ suma, Walras fue librepensador, republicano, pacifista, publicista político activo, fundador de cooperativas, defensor de la propiedad estatal de la tierra... algo que en sus días, tanto en la Francia de la restauración como en la neutral Suiza, le situaba en la izquierda del espectro político, pero en la tradición del reformismo radical, enfrentado al socialismo revolucionario. Sus creencias - defendidas con ardor, insistencia y agresividad en forma públicano debieron resultar del agrado del poder político y económico, lo que pudo hurtarle apoyos institucionales, pero en modo alguno justificar su limitado éxito en vida como economista ${ }^{9}$. Sin embargo, como veremos enseguida, estas posiciones políticas sí constituyeron una razón de peso para que la historiografía de las doctrinas económicas nos haya legado una visión reduccionista de su obra.

\section{WALRAS EN LA HISTORIOGRAFIA DEL PENSAMIENTO ECONOMICO}

La obra de Walras ha llegado a nuestros días como caracterizada por dos rasgos fundamentales. Ser el codescubridor de la teoría de la utilidad y haber formulado por vez primera un modelo de equilibrio general competitivo, no mencionándose casi nunca la existencia de una dilatada obra dedicada a temas de economía aplicada y social. Walras aparece, en suma, en el mejor de los casos, como un economista teórico de primera magnitud -muchas veces ni siquiera esto- y como veleidoso proponente de medidas de política económica carentes de fundamentación científica, producto de prejuicios ideológicos.

En un trabajo reciente, Jaffé (1980) señala como responsables de esta visión reduccionista y sesgada a Pareto, Hicks y Schumpeter. La influencia de estos autores sobre la visión heredada de Walras es importante, y por ello la analizaremos con detalle en este epígrafe. Sin embargo, una idea precisa de la historiografía de Walras requiere la consulta de otras fuentes. En par-

- La urevolución» preconizada por Walras consistía en la adquisición -no confiscación- de las tierras por el Estado, financiada con los ingresos obtenidos mediante el gravamen de la renta de la tierra durante largo período de tiempo ( $\mathrm{L}$. Walras, $1881 b$ ). En todo caso, el texto en que mejor se reflejan las concepciones de Walras en materia política y social es el de 1898 a.

- El único éxito en vida fue su Jubileo, celebrado el 10 de junio de 1909 -medio año antes de su muerte-, en el que se descubrió una placa en su honor a la entrada de la Universidad de Lausanne y al que llegaron numerosas felicitaciones de académicos y economistas suizos, ingleses, italianos, estadounidenses, austriacos... 
ticular, resulta significativa la diferenciación entre dos períodos: el anterior y el posterior a la edición de los EEPP realizada por Jaffé. Dentro del primero — además de Pareto, Hicks y Schumpeter- se analizarán aquí dos libros de historia del pensamiento económico que presentan visiones de la obra de Walras, interesantes por razones distintas: el de Gide y Rist (1909) y el de Hutchinson (1953). En el período post-Jaffé los nombres serán Friedman, Harrod, Blaug, Barber, Rugina y Morishima.

Pareto, como ya hemos mencionado, tenía una excelente opinión de Walras como teórico, pero disentía radicalmente de él, tanto en algunos aspectos técnicos como, sobre todo, en lo referente a la economía aplicada y social. Las divergencias en el campo analítico se refieren fundamentalmente a la concepción restringida que Walras tenía de la utilidad y a su negativa a aceptar que la economía tuviera componente alguno de ciencia experimental. Estas diferencias, sin embargo, no sólo son limitadas, sino que afectan al campo del análisis puro $\mathrm{y}$, por tanto, no a la visión global de la obra de Walras, cuyos orígenes rastreamos.

Más importantes en este aspecto son las divergencias frontales en materia de economía aplicada y social. Aquí la opinión de Pareto es claramente crítica, y se expresa en forma contundente. Sobre la teoría walrasiana de la propiedad, opina en 1896 que «Walras publica cosas increíbles. Tú [Pantaleoni] eres más joven que yo. Cuando escriba cosas de este género te ruego me adviertas de inmediato» (De Rosa, 1960, vol. I, p. 456); sobre el discurso de Walras en su Jubileo de 1909, «Espero que el Giornale degli Economisti no publique el increíble discurso de Walras» (ibid., vol. 3, p. 139); comentando la crítica recibida al primer volumen de su Cours de 1896 , «Walras vive ahora en las nubes con su metafísica, andando como un astrónomo que hubiera caído en un pozo» (ibid., vol. 1, p. 430).

Si bien las divergencias son manifiestas, la influencia de Pareto sobre la historiografía walrasiana cabe suponer que es prácticamente nula. No sólo Pareto es un autor casi tan poco leído como Walras en lo que se refiere a sus aportaciones analíticas puras, sino que sus críticas a éste en el área de la economía social aparecen tan sólo en dos notas a pie de página de su Tratatto sociológico (Pareto, 1916) -no existe mención alguna en el Compendiumy en su correspondencia con Pantaleoni, que se empieza a publicar en 1960, $y$ no es precisamente un libro de cabecera.

La responsabilidad de Hicks es mayor porque su artículo de 1934, publicado con motivo del centenario del nacimiento de Walras y mucho antes de la edición de Jaffé de los EEPP, sí fue profusamente leído a tenor de las citas realizadas del mismo. El trabajo de Hicks consiste en una evaluación de las Secciones II-VI de los EEPP positiva en lo relativo a la teoría del intercam- 
bio; muy elogiosa para la teoría de la producción y de la formación de capital, de la que llega a afirmar que con pequeñas modificaciones es superior a la de Böhm-Bawerk y tan satisfactoria como la de $\mathrm{K}$. Wicksell; y muy negativa sobre la Sección VI y el resto de su obra: «Del trabajo de Walras en teoría monetaria y sus escritos comparativamente faltos de interés sobre economía aplicada no nos ocuparemos aquím (Hicks, 1934, p. 347).

No se puede, sin embargo, responsabilizar a Hicks de la visión reduccionista de la obra de Walras, es decir, de la omisión de los elementos de economía aplicada y social, porque su trabajo está dirigido a comentar los EEPP y es más que plausible suponer que no hubiera leído los Etudes d'economie politique appliquée (EEPA), ni los Etudes d'économie sociale (EES), en los que se reúne la obra de Walras en estos campos. Sin embargo, sí es responsable de una lectura sesgada, pero muy difundida, de los EEPP, según la cual lo relevante de los mismos es tan sólo el modelo de equilibrio general con numerario, pero sin dinero (Secciones II-V) ${ }^{10}$, visión ésta que hurta al lector todos los planteamientos metodológicos de Walras y que le hace aparecer como un autor vulgar en el campo de la teoría monetaria.

El papel de Schumpeter en la creación de una visión reduccionista de Walras resulta decisivo por un doble motivo. Primero, porque sus trabajos (1951, 1954) constituyen la fuente principal de conocimiento de la obra de Walras para los economistas - y cabe sospechar que también para muchos historiadores del pensamiento económico. Segundo, porque de la presentación que hace de Walras emerge una imagen de su obra formada por dos conjuntos independientes: los EEPP, obra cumbre del análisis económico, y el resto, literatura de tercera fila.

La opinión sobre el Walras teórico es la más positiva de todas las existentes: desde el calificativo de aere perennius, aplicado a las Secciones II-VI de los EEPP (Schumpeter, 1951, p. 113), hasta el de más grande de todos los economistas, creador de «la estática económica, la teoría moderna del equilibrio económico, y (...) la teoría monetaria moderna» (Schumpeter, 1954, p. 1082), afirmación esta última en clara contradicción con la opinión de Hicks y, sin duda, influida por los excelentes trabajos de A. W. Marget (1931, 1935). No es aquí lugar para entrar en una descripción de la opinión de Schumpeter sobre los EEPP, pero sería injusto no señalar que las páginas 999. 1026 de la History constituyen una visión brillante y genial de las Leccio

10 Es decir, eliminando del comentario la discusión sobre metodología; la diferenciación entre economía pura, aplicada y social; la teoría del valor basada en la rareté (escasez+utilidad) de la Sección I; los elementos semidinámicos y la crítica a fisiócratas y clásicos ingleses de la Sección VII, y las teorías de la competencia imperfecta e imposición de la Sección VIII. 
nes 5.35 de los EEPP ". Quizá esta misma brillantez haya convencido a muchos de la posibilidad de sustituir, sin mermas de comprensión, 461 páginas por 27; pero esto es algo de lo que Schumpeter es inocente.

El desequilibrio aparece en cuanto el austríaco habla de la obra no teórica de Walras. Con sólo tres excepciones ${ }^{12}$, su pesarosa opinión es que «Desgraciadamente, el propio Walras concedió excesiva importancia a su discutible filosofía sobre la justicia social, su esquema de nacionalización de la tierra, sus proyectos de organización monetaria y otras cosas que nada tienen que ver con su soberbio logro en el campo de la teoría pura (Schumpeter, 1954, p. 828). Es claro que esta opinión es sostenible, aunque hubiera sido más adecuado que se encontrara razonada y no sólo formulada taxativamente, pero lo grave de la misma no es tanto su contenido cuanto el hecho de que aparece magnificada en el contexto de sus obras, porque este tipo de afirmaciones se omite o mitiga cuando se trata de otros autores relevantes. El análisis de los casos de Gossen y Pareto bastarán para convencernos de ello.

El caso de Gossen es ilustrativo de la asimetría comentada. Este autor es profusamente citado, pero en ningún lugar de la History se hace referencia a que defienda la propiedad estatal de las tierras. La cuidadosa lectura que Schumpeter tuvo que hacer de la obra de Gossen - por otra parte no muy extensa- $\mathrm{e}$ incluso la familiaridad con la misma, habida cuenta de los orígenes de ambos, impide suponer que aquél desconociera la posición del alemán. Pero es que, incluso, Walras $(1881 \mathrm{~b})$ menciona en forma expícita a Gossen como antecedente de la propuesta de que el Estado adquiera la tierra amortizando su coste de adquisición mediante el gravamen de la renta que genera. Es una omisión a señalar habida cuenta de la precisión y detalle de la obra de Schumpeter, aunque quizá se explique por el hecho de que Gossen no fue un autor tan importante como para ocuparse de los aspectos no puramente analíticos de su obra.

Sin embargo, esta excusa no cabe con Pareto, y aquí la asimetría en el tratamiento de Walras es incuestionable. Sin más que consultar el índice onomástico de la History, nos encontramos con que, mientras Walras aparece como «semisocialista», Pareto es calificado de «liberal peculiar» y «positivista y laico»: ¿por qué no como «semifascista»? Pero la simpatía ideológica de

"Interpretación más meritoria aún, tal y como ha llegado a nuestras manos, si se tiene en cuenta que, como se señala en el Apéndice del editor a la History (p. 1200), el epigrafe «Sistema walrasiano de equilibrio general se encontraba sin acabar cuando murió el autor.

${ }_{12}$ Las excepciones son la «ingeniosaw propuesta de sistema bimetálico con acuñación de plata con fines reguladores ( $L$. Walras, 1884; Schumpeter, 1954, p. 1079), la contribución a la construcción de números índices (L. Walras, 1874, 1885; ibid., p. 1093) y el carácter cíclico de la producción de bienes de capital (L. Walras, 1898 ; ibid., p. 1126 n.). 
Schumpeter por el noble italiano se pone de manifiesto sin ambages cuando se comprueba que la History no contiene una sola línea en que se intente explicar el porqué de las posiciones político-económicas defendidas por Walras, y existe, sin embargo, un largo y apasionado párrafo en que, sin mencionar el hecho de que Pareto llegara a ser senador por designación de Mussolini, se intentan justificar las raíces de su «peculiar liberalismo» (Schumpeter, 1954, p. 860):

Pero su liberalismo, económico y político, fue de tipo peculiar y de peculiares raíces. Fue un hombre de fuertes pasiones; pasiones del tipo que impiden a un hombre ver más de un aspecto de un tema político, o de una civilización. Esta disposición se vio reforzada, más que mitigada, por su sólida formación clásica, que lehizo tan familiar la antigüedad como con la Italia y Francia de su tiempo (...). Y observando con ira apasionada los actos de los políticos de las democracias liberales italiana y francesa, se convirtió, por indignación y desesperación, a una actitud anti-étatiste que, como los hechos demostrarían, no era realmente propia. Añádase a esto el hecho de que fue (como Marx) al mismo tiempo un producto de la civilización que odiaba y, por tanto (también como Marx), positivista y laico, y podrá entenderse la superficie liberal de sus primeros escritos.

Es difícil, en una obra tan soberbia, encontrar un intento más trabajoso, innecesario y, en mi opinión, erróneo ${ }^{13}$ de justificación de las posiciones políticas de Pareto. Y, como resulta evidente, a esto no son en absoluto ajenas las afinidades sociales y simpatías ideológicas que Schumpeter sentía por $\mathrm{Pa}$ reto, ni la incomodidad que tenían que producirle los aspectos humano y politico de una personalidad como la de Walras.

La asimetría señalada se hace todavía más patente en los ensayos individuales de Schumpeter (1951). Frente a las 8 páginas dedicadas a Walras, Pareto ocupa 39 , y las descripciones de las posiciones políticas de ambos son por demás significativas - no casualmente, ambas en el ensayo sobre Pareto-, "Walras presentó su inmortal teoría bajo la forma de una filosofía política, que era de naturaleza extracientífica y que, además, no podía ser del gusto de todos. Me temo que no haya mejor forma de expresar lo que esta filosofía

${ }^{13}$ Erróneo salvo que todos los liberales sean peculiares en el sentido schumpeteriano de la expresión, sea éste el que sea. En materias de economía política, Pareto fue siempre un liberal puro, lo que con ironía califico Walras como eescuela de los "anarquistas de cátedra" (CRP, carta 1136). Baste recordar las recomendaciones a Mussolini, realizadas al final de su vida (véase Bousquet, 1928, pp. 182 y ss.). 
era que definiéndola como la del radicalismo burgués" (Schumpeter, 1951, p. 170). Como si existiera una filosofía política de naturaleza científica en sentido schumpeteriano. Sin embargo, en Pareto todo encuentra justificación: ante el caos de la situación italiana debió pensar como solución, y debido a su formación clásica, en la institución del Senado de la República romana, que permitía a los cónsules nombrar un dictador temporal (ibid., p. 168).

Para terminar con el análisis de textos sobre Walras anteriores a la edición de Jaffé de los EEPP, merece la pena mencionar dos libros de historia de las doctrinas que, como tendremos ocasión de ver, resultan, por distintos motivos, muy superiores a los actuales desde la perspectiva que aquí nos interesa.

El primero de los libros que creo útil comentar, el de Gide y Rist (1909), presenta un enfoque curioso de la obra de Walras. Pese a tratarse, por razones evidentes, de un libro obsoleto, resulta una lectura recomendable, sobre todo, para ver cuál era la idea que unos historiadores del análisis económico tenían de la aportación de Walras a la economía en su propio tiempo. Lo más significativo es la modesta valoración de la obra teórica frente a la gran importancia concedida a los aspectos sociales y políticos. La primera mención analítica a Walras aparece, después de haber discutido la crítica a los clásicos in. gleses y la teoría de la utilidad, en el epígrafe sobre «La escuela matemática» (Libro V, cap. I, $\ 3$ ) en una nota a pie de página que reivindica a Walras como francés y no como suizo. El juicio sobre la importancia de Walras en este terreno se confina a una nota (p. 587) y a través de una cita de Pareto ${ }^{14}$. Walras aparece en el texto principal de forma extensa sólo cuando se le define como «socialista agrario» (pp. 596 y ss.) y, más adelante, en el epígrafe sobre los «Sistemas de nacionalización del suelo» (Libro V, cap. II, $\$ 3$ ), donde existe una exposición detallada de su posición sobre el tema (pp. 628-632).

La obra de Hutchinson (1953) es quizá la única recomendable para tener una visión aceptablemente general de Walras. El capítulo XIII constituye una exposición competente y completa de las aportaciones teóricas y políticas del francés; y si bien pueden encontrarse explicaciones más articuladas de los $E E P P$, de la que proporciona una exposición por orden de las Secciones II a VI, no se puede encontrar un comentario más equilibrado y representativo del Walras no teórico que el contenido en las 5 páginas dedicadas a «Las Teorías de Walras sobre Economía Aplicada y Social», que se cierran con una infrecuente afirmación: «Aun cuando nunca fueron sistemáticamente completados, los dos volúmenes de Walras sobre política económica [EEPA y EES] son un gran intento, como el libro III de Sidgwick, de revisión sistemática de la política económica» (p. 222).

${ }^{14}$ Lo que resulta irónico habida cuenta de que, en carta de Walras a Gide, aquél expresaba en 1903: «Sobre todo no me confundáis con Pareto, buen matemático, pero nulo como filósofow (CRP, carta 1539). 
Todos los autores comentados hasta aquí pertenecen al período pre-Jaffé de la historiografía walrasiana. Cabría pensar que la aparición de la versión inglesa de los EEPP, y la interpretación más equilibrada y completa de la obra de Walras que en la misma subyace, deberia haber conducido las aguas a su cauce normal. Lejos de ser así, dicha edición tuvo como efecto cierto reforzamiento en medios académicos cultos de la idea de que Walras era sólo los EEPP e, incluso, supuso la aparición de dos trabajos en revistas especializadas de gran circulación profesional y de autores muy prestigiosos - Friedman (1955) y Harrod (1956) - con opiniones sobre la aportación analítica de Walras que, leídas hoy día, bordean casi el ridículo. Cabe suponer que, pese a ello, tuvieron un considerable peso en la interpretación más generalizada de Walras y que se les ha atribuido una importancia muy inferior a la que realmente tuvieron en la creación de una visión reduccionista. Por ello me detendré brevemente en su comentario.

El trabajo de Friedman es una lectura de los EEPP à la Hicks, pero más extremada - ni siquiera las Secciones II-VI, ya que excluye totalmente la teoría monetaria de la Sección VI, algo curioso precisamente en este autory menos competente. Para Friedman, "al mayor nivel de generalidad hay dos temas principales en los Elements (sic): el análisis de la rareté, o utilidad marginal, y la teoría del equilibrio general» (p. 900). En el tema de la rareté todo lo que aparece es una crítica al tratamiento innecesariamente metafísico que de la misma hace Walras, cabe suponer que entendiendo como tal el hecho de que para construir la teoría no es necesaria la rareté walrasiana como magnitud absoluta, bastando con los cocientes entre raretés, tema éste que constituye el objetivo, mucho más matizado, de una nota de Jaffé (1954, n. 1, Lección 5, p. 498; versión española, pp. 252-253).

A partir de aquí, Friedman señala como «la gran contribución de Walras» el «proveer de un lenguaje, un esquema clasificatorio para organizar materiales» (p. 906), para terminar con la siguiente evaluación global de la aportación walrasiana (p. 908):

La economía no sólo requiere un marco para organizar nuestras ideas, precisa también de ideas a organizar. Necesitamos el tipo de lenguaje adecuado, pero también algo que decir. Hipótesis sustantivas sobre los fenómenos económicos del tipo de las que fueron objetivo de Cournot son un ingrediente esencial de una teoría económica fructífera y con sentido. Walras tiene poco que contribuir en esta dirección; para ello hay que volver a otros economistas, especialmente, por supuesto, a Marshall. 
Puestos a buscar justificaciones, tras la opinión de Friedman se encuentra su conocida postura sobre la metodología de la economía, su clara decantación por el análisis parcial y la omisión del equilibrio general, característica de su obra anterior y posterior. Pero la exclusión de toda referencia a la teoría monetaria contenida en los EEPP y su opinión global sobre éstos es más que significativa de una valoración no sólo unilateral, sino también notoriamente sesgada.

La calidad del artículo de Harrod es aún inferior. Su único objetivo parece más bien entonar una loa a los clásicos ingleses y demostrar la profunda influencia de los mismos sobre Walras, así como la superioridad de Marshall sobre éste y el papel más importante de Keynes en la historia económica. Preguntándose por el lugar que debería ocupar Walras en la secuencia de «modelos de tipo genérico», representada para el autor por Smith $\rightarrow$ Ricardo $\rightarrow$ $\rightarrow$ Marshall y J. M. Keynes, manifiesta una opinión cuya simple transcripción hace innecesario todo comentario (p. 309):

Si se contempla el trabajo esencial de Walras como el dar una prueba completa, final y pulida del teorema central de Adam Smith [la mano invisible], debe seguirse de ello que no debería ocupar en la historia de la economía la posición que tiene un gran pionero como J. M. Keynes, sino más bien uno semejante al ocupado por su padre, J. N. Keynes, en la historia de la lógica. J. N. Keynes proporcionó una demostración tan completa y pulida de la lógica silogística que nadie, antes ni después, ha podido mejorar. (En justicia a J. N. Keynes, debe añadirse que su lucidez y presentación fueron muy superiores a las de Walras.)

A partir de los artículos originados por la aparición de la versión de Jaffé de los EEPP ${ }^{15}$, la literatura sobre Walras se bifurca por diversas vías. Por una parte, su figura va apareciendo tratada en los nuevos libros de historia de las doctrinas económicas; por otra, algunos autores hacen aportaciones parciales a aspectos concretos de los EEPP, entre las que cabe destacar la secuencia de trabajos de Jaffé en su proceso de preparación de la correspondencia de Walras (CRP, 1965). Aparecen también unas pocas interpretaciones más globales de Walras, pero quizá el efecto más notorio sea el rapto y formalización del francés por parte de la naciente teoría matemática del equilibrio general competitivo. De todo este conjunto de literatura elegiré unas pocas muestras. Los trabajos de tipo puntual - v. gr., sobre la teoría

is Cabe citar también, entre los artículos generados por la edición de Jaffé, el de R. E. Kuenne (1956) - de menor influencia profesional que los de Friedman y Harrod-, que contiene un comentario sumamente elogioso de la estructura interna global de los EEPP. 
monetaria, el papel de los tâtonnements, el óptimo social, etc. ${ }^{16}$-, siendo fundamentales para realizar una valoración más correcta de la obra de Walras, son aquí de interés secundario porque no conforman directamente la imagen global de dicha obra. El rapto matemático tampoco requiere estudio alguno por encontrarse, como es natural, dentro de la visión hicksiana de Walras. Sólo dos aspectos merecen cierta atención: el tratamiento dado en los libros de historia del pensamiento y la existencia de algunas interpretaciones más globales.

Por lo que respecta a los libros de historia, con frecuencia importantes no desde el punto de vista de las aportaciones u originalidad en el análisis de los autores, sino por ser, de hecho, los transmisores reales de la imagen de la mayoría de aquéllos, los de Blaug (1966) y Barber (1967) son merecedores de algún comentario, no por su calidad, sino por ser de amplia utilización y contener casi todos los defectos de la visión walrasiana más sesgada y errónea ${ }^{17}$.

El libro de Blaug es anglocéntrico, sesgo limitativo, pero tolerable, si no fuera por lo extremado del mismo: las "Guías del lector" que incluye, con el objeto de «alentar a los estudiantes a familiarizarse directamente con las principales obras del tema a que se dediquen» (p. 8), tratan sólo de Smith, los Principles de Ricardo, J. S. Mill y Marshall, el Common Sense de Wicksteed, Marx y las Lectures de Wicksell. Esto ya preludia el tratamiento de la obra de Walras, que, sin embargo, supera todas las expectativas en cuanto a errores, imprecisiones y ambigüedades. La simple enumeración de algunas de ellas será suficiente: señala que para Walras la competencia maximiza la satisfacción de todos los miembros de la sociedad, sin especificar bajo qué precisas condiciones (véase Jaffé, 1954, n. 1 a la Lección 10, pp. 510-511; versión española, pp. 265-267); afirma que Walras trazó funciones lineales de utilidad marginal en su libro, algo que sólo hizo en la primera edición de 1874 y que eliminó en las siguientes precisamente para evitar errores de interpretación (CRP, carta 412 a Jevons de 1878); le califica de "reformador agrario», confundiendo la posición de Walras sobre la propiedad de la tierra y la financiación del Estado con el reformismo agrario; sentencia que antes de la década de 1890 no se resuelve el tema de la relación entre la utilidad y la demanda para afirmar, pocas páginas después, que Walras y luego Marshall dedujeron clara y explícitamente las curvas de demanda de las de utilidad; destaca que Walras rindió tributo a las cualidades de los trabajos de Dupuit, confundiendo su acuerdo con el uso del método matemático con la opinión de que

${ }^{16}$ Entre los que tienen especial interés, Kuenne (1961), sobre la teoría monetaria walrasiana; Walker (1970), sobre diversos aspectos de la obra walrasiana; Jaffé (1977), sobre el óptimo social, y Jaffé (1981), sobre el tâtonnement. pañola.

17 Ambos, además, han sido profusamente utilizados en la docencia universitaria es- 
nada aporta al trabajo de Cournot y de que en lo principal -el excedenteestaba equivocado (L. Walras, 1926, $\$ 385-387$ ). Incluso menciona 1886 como fecha en que Walras, por vez primera, une su nombre a los de Jevons y Menger como codescubridores de la teoría de la utilidad.

Con un conocimiento tan indirecto e impreciso de Walras, el libro dedica dos decenas de páginas a explicar sus aportaciones analíticas. Como ejemplos de dónde se coloca el énfasis bastarán tres. Blaug dedica un 10 por 100 del comentario a explicar que aunque el número de ecuaciones e incógnitas de un sistema coincida puede no tener solución o no ser única, problema que califica de «sutil», aportando para su comprensión ejemplos del tipo $x^{2}+y^{2}=0$, $x^{2}-y^{2}=1$, para concluir que la demostración de la existencia del equilibrio en Walras es insatisfactoria porque no se percibió de que se deben incluir también los bienes no económicos -es obvio que, aunque los hubiera tenido en cuenta, tampoco habría demostrado la existencia (véase Segura, 1987, pp. 38 y 54, n. 48)-. El segundo ejemplo es la página escasa dedicada a la teoría monetaria en la que no se menciona por qué el dinero tiene utilidad aunque no sea un bien de consumo con utilidad directa, lo que constituye la clave para introducirlo en un modelo en que las funciones de demanda se derivan de las de utilidad, y es la verdadera innovación analítica que permite pasar de un enfoque de circulation à desservir a otro basado en el encaisse desirée. El último ejemplo es la teoría del capital walrasiana: en la página que le dedica aparece el bien $E$ como «un tipo especial de bien de consumo», cuando es una renta anual perpetua cuyo único objetivo es poder expresar en términos homogéneos el capital total de la economía.

Tras este recorrido, poco puede extrañar que la valoración final de Walras sea $\tan$ confusa y ambigua como todo lo anterior. Para Blaug, «la economía walrasiana, en este punto como en todos los demás, posee escasa sustancia, dando prioridad a la forma a expensas del contenido» (Friedman, dixit). Pero no nos preocupemos, nuestro autor perdona a Walras pocas líneas después: «Podemos mostrarnos un poco caritativos al pasar por alto las debilidades de sus obras, puesto que la única cosa importante que sabía, la interdependencia de todos los precios y cantidades, fue, quizá, la primera idea verdaderamente nueva que surgió en la ciencia económica desde la época de la Riqueza de las Naciones.» Por fortuna, resulta imposible encontrar otra combinación similar de arrogancia ignorante.

El libro de Barber es, desde el punto de vista del anglocentrismo, más extremado, incluso, que el de Blaug, bastando para comprobarlo la composición del capítulo dedicado a la economía neoclásica: 30 páginas para Marshall y 16 para el conjunto de Walras, Clark, Böhm-Bawerk y Wicksell. Pero lo más significativo es el propio tratamiento de Walras: sus EEPP se reducen 
a la teoría del intercambio puro - sólo Secciones II y III - y los comentarios valorativos se refieren a la imposibilidad de tratar problemas de subempleo de recursos o de rendimientos crecientes de escala en el marco de su modelo, para terminar con un párrafo que demuestra un desconocimiento del conjunto de la obra comentada: "Walras estaba personalmente a favor de un régimen de pequeños terratenientes, arreglo institucional capaz de aproximarse a la competencia perfecta más que ningún otro sistema imaginable» (p. 215).

Para terminar este recorrido historiográfico sobre $W$ alras, dos menciones adicionales: Una primera, el desigual trabajo de Rugina (1982) que, pese a ello, tiene la ventaja de tratar de hacer una evaluación integral de la obra de Walras, si bien la presenta en forma un tanto esquizofrénica como producto de la superposición de la existencia de «dos walrases»: el «científico puro» y el «reformador social». Sin embargo, su lectura es sugerente por tres motivos. Primero, ofrece una versión de Walras conectada -en algunos casos de forma muy alambicada - con los problemas económicos actuales. Segundo, da cuenta sesgada, pero amplia, de la obra no analítica de Walras. Tercero, utiliza las referencias con precisión y explica las posiciones de Walras en forma documentada. Aspectos todos ellos ausentes en la casi totalidad de la literatura comentada.

El libro de Morishima (1977) constituye una obra peculiar por diversos motivos. En primer lugar, se trata de una interpretación de los EEPP que - como el subtítulo indica- centra su atención en las teorías de la formación de capital y monetaria walrasianas, es decir, en uno de los aspectos considerados menos relevantes según la tradición hicksiana. En segundo lugar, pese a tratar sólo de los EEPP, su reinterpretación de éstos se apoya en la estructura de clases subyacente en Walras, en la idea que el autor tenía de la justicia y del problema social, y en la importancia concedida a la Sección VII — «Condiciones y consecuencias del progreso económico»-, normalmente considerada una simple coda a los EEPP ${ }^{18}$. Por último, aunque no considera de forma explícita los aspectos de economía aplicada y social de la obra walrasiana, Morishima insiste por dos veces en el Prefacio de su libro en la importancia de los mismos y en cómo las aportaciones en el campo aplicado están conectadas con el análisis teórico (pp. iv y vii). No obstante, y pese a su calidad, la obra de Morishima se sitúa más que en el campo de la interpretación de Walras en el de la «ampliación del análisis del equilibrio general en la exploración de áreas que L. W. no tuvo en consideración" ${ }^{19}$, constituyendo una versión libérrima de los EEPP.

" El lector interesado en la obra de Morishima encontrará muy sugerente y esclarecedora la polémica mantenida entre Jaffé (1980) y Morishima (1980).

19 Walker (1980), p. 135. Este trabajo constituye una excelente crítica de Morishima (1980). 
Pese al interés del texto de Morishima, es dudoso que haya ejercido influencia alguna contra la visión reduccionista de la obra de Walras que hemos discutido en este epígrafe. Por una parte, se trata de un texto de difícil lectura, accesible sólo a una exigua minoría de economistas con buena formación matemática. Por otra parte, el tipo de lector a quien va dirigido es, precisamente, el más interesado tan sólo en los aspectos formales de la obra de Walras.

\section{UN INTENTO DE INTERPRETACION CONJUNTA DE LA OBRA DE WALRAS}

¿Fue la obra de Walras un todo integrado?, ¿fue, por el contrario, la superposición de tres planos - analítico, aplicado y social- inconexos o, cuando menos, separables? La versión generalmente aceptada, documentada en el epígrafe precedente, ha consagrado en el mejor de los casos una visión fraccionada, según la cual su obra puede separarse en dos conjuntos: uno fundamental, los EEPP y las memorias analíticas, ubicado en el campo de la economía teórica pura, y otro ignorable, cuando no muy deficiente o carente de interés, formado por los EEPA, los EES y todos los trabajos de economía aplicada y social.

Esta no era, en absoluto, la idea del autor sobre su propia obra. En fecha tan temprana como 1859 , a los 25 años, Walras ya había pergeñado con detalle un plan de trabajo encaminado a «dar una solución científica al problema de la Distribución de la Riqueza» ( $C R P$, carta 16), que contenía un esquema casi definitivo de las investigaciones a realizar a lo largo de su vida, y que posteriormente confirmó en 1862 en un «Programa sucinto de un Tratado completo de economía politica y social» (CRP, carta 81 ) y en la propuesta de un programa docente de Lausanne para 1871 (CRP, carta 171), y en todos ellos su programa de investigación contempla los aspectos puros, aplicados y sociales como un todo integrado.

Sería absurdo, a más de irrelevante, negar que las aportaciones más importantes de Walras se sitúan en el campo de la teoría pura, pero resulta erróneo considerar su obra separable en dos conjuntos disjuntos. Es claro que quien lo desee puede interesarse sólo en la obra puramente analítica de Walras, de la que obtendrá enseñanzas, pero en ese caso carecerá de una visión completa de sus trabajos, no conocerá la génesis real de su obra y no debería, por tanto, emitir opiniones sobre el papel de Walras en la historia del pensamiento económico. Lo que trato, en suma, de probar en el resto de este trabajo es una proposición que cabría formalizar en los siguientes términos: 
Si se aceptan:

i) la diferenciación que Walras bace entre economia pura, aplicada y social, y

ii) la conclusión principal de su modelo de equilibrio general competitivo.

\section{Entonces:}

A) no es posible rebatir, desde el punto de vista lógico, sus opiniones en materia de economía aplicada -que se refieren a temas centrales de política económica-, y

B) las posiciones walrasianas en materia de economía social resultan, lógicamente, coberentes con su esquema teórico, aunque puedan ser no compartidas desde el punto de vista ideológico.

$\mathrm{Y}$ si esto es cierto, se derivan como corolarios que:

a) la lectura à la Hicks de los EEPP impide una interpretación correcta de la obra al omitir sus aspectos metodológicos - Sección I-, semidinámicos - Sección VII- y de competencia imperfecta - Sección VIII-, y

b) la obra de Walras en el campo de la economia aplicada y social es de alta calidad y relevante para su época.

i) Los diferentes planos del análisis económico en Walras

La posición metodológica de Walras data de fecha muy temprana (1859a) en que ya señalaba que la ciencia "observa, describe, explica» y el arte «aconseja, prescribe, dirige», que la ciencia ilumina al arte y éste aplica los resultados de aquélla. El objeto de la economía es la riqueza social, que no es más que el conjunto de cosas escasas en sentido científico, es decir, útiles y limitadas en cantidad. Todos los componentes de la riqueza social tienen, pues, valor, y por ello son apropiables, intercambiables y reproducibles por medio de la actividad industrial. De ahí que un estudio completo de la riqueza social deba plantearse tres problemas distintos, que dan lugar a tres tipos de análisis económico:

- A qué se debe y cómo se genera la riqueza social. El objetivo de este análisis es la teoría del valor de cambio, que constituye el núcleo de la economia política pura. 
- Cómo se produce la riqueza social. El objetivo de este análisis es la teoría de la industria, que constituye el núcleo de la economía politica aplicada.

- Cómo se apropia y distribuye la riqueza social. El objetivo de este análisis es la teoría de la propiedad, que constituye el núcleo de la economía social.

¿En qué se diferencian, para Walras, estos tres planos de análisis, además de en su objetivo explicativo?: en el criterio rector de cada uno de ellos. En el campo de la economía política pura el criterio es la veracidad, porque se trata de una ciencia físico-matemática de carácter puramente deductivo sin componente experimental alguno. En la economía aplicada el criterio será la realidad, ya que se trata de ver en qué forma cabe aplicar a la misma las conclusiones obtenidas por la ciencia pura; constituye, pues, un conocimiento de tipo práctico. Por último, la economía social debe regirse por el criterio de justicia, situándose en el ámbito de las ciencias morales (EEPP, \\$30, 38, 39).

Walras defendió ardientemente el derecho del científico puro en cuanto tal a plantearse problemas abstractos, con independencia de su realismo, aplicabilidad o interés práctico; pero siempre sostuvo de forma explícita que el resultado global del estudio de la economía era «no el máximo absoluto de interés, sino el máximo absoluto de interés compatible con la justicia» (CRP, carta 652).

\section{ii) La conclusión principal del análisis del equilibrio general}

Walras partió de una clara preconcepción analítica: su convencimiento de que la competencia perfecta era el mejor de los sistemas, desde el punto de vista de lo que hoy día llamamos eficiencia. La demostración de esta idea es el objetivo central de todo su análisis en el campo de la economía política pura, y, en efecto, demostró, en sus propias palabras, que la competencia era el sistema que, bajo ciertas condiciones, mejor satisfacia el objetivo de maximizar el interés material, con independencia de que fuera o no compatible con la justicia. Esta es una afirmación universalmente admitida por el análisis económico actual, pero es precisamente el hecho de que dicha afirmación sea cierta sólo bajo ciertas condiciones lo que constituye la clave para enjuiciar la coherencia de las propuestas walrasianas en el campo de la economía política aplicada.

¿Cuáles son estas condiciones? La principal, la uniformidad de los precios, es decir, que los precios sean los mismos para todos los agentes (L. Walras, 
1926, Lección 10). Walras era consciente de que «si las mercancías se vendieran caras a los ricos y baratas a los pobres (...) se produciría un gran aumento de la utilidad efectiva [global]» (CRP, carta 652). Pero defender o no la discriminación sería, en todo caso, un tema de economía social del que por ahora nos mantendremos al margen. A esta condición añadió: que el consumidor sea capaz de estimar la utilidad de los bienes y servicios y que el beneficio sea nulo (L. Walras, 1926, $\$ 223$ ).

\section{A) La no rebatibilidad lógica de las opiniones de Walras en materia de economia pura.}

Resulta ahora fácil repasar la lista de las posiciones mantenidas por Walras en economía aplicada para demostrar su escrupulosa coherencia con la teoría:

- Defendió el librecambio internacional, combatiendo aranceles y prácticas restrictivas de todo tipo antes y después de los EEPP (v. gr., 1861 a, 1897 b). La fundamentación de esto se encontraba en que las ventajas del intercambio libre entre países permitiría mejorar las utilidades efectivas de todos, un resultado teórico poco discutible.

- Consideró que los impuestos sobre el consumo, sobre las rentas del capital y sobre los salarios distorsionaban la competencia, y que sólo un impuesto sobre las rentas de las tierras era neutral, y atacó los primeros y defendió el segundo antes y después de los EEPP (v. gr., $1860 a, 1861 \mathrm{a}$, 1896 c). En la medida en que la tierra era el único bien de capital cuya cantidad consideraba fija —como los clásicos-, su análisis de incidencia y traslación fue impecable (véase EEPP, Lección 42), porque los efectos sobre la distribución de la riqueza pertenecen a otro ámbito del análisis.

- En el campo de la politica monetaria fue liberal estricto, oponiéndose a controles de no convertibilidad, siendo partidario de que el tipo de interés de mercado regulara los movimientos monetarios y financieros internacionales $(1861 b)$ y contrario al monopolio de emisión de billetes de banco $(1879 b)$.

- Sus aportaciones a la teoría monetaria aplicada fueron más que notables, y de ellas se benefició su elaboración teórica, en continua mejora desde la primera edición de los EEPP, en que la demanda de dinero se determinaba en forma empírica, hasta la tercera, en que aparece el enfoque de saldos líquidos deseados y se consigue dotar de utilidad al dinero no mercancía vía los servicios de disponibilidad que presta ${ }^{20}$.

${ }^{20}$ La evolución detallada de la teoría monetaria walrasiana entre ediciones de los EEPP se encuentra en Marget (1935). Una versión más accesible y simplificada, en Jaffé (1954, notas del traductor a la Lección 29). 
Una de sus preocupaciones centrales en este área fue el logro de la estabilidad del valor del dinero. Partiendo de que la unidad monetaria no constituye una unidad de valor (1867 a), analizó los problemas de la Unión Monetaria Latina, las relaciones monetarias anglohindúes y los efectos del descubrimiento de nuevos yacimientos de metales preciosos, realizando aportaciones a la contrastación empírica de la teoría cuantitativa $(1885 b)$ y al empleo de números indices en este tema (1885 a). Su propuesta básica, un sistema bimetálico con acuñación de plata con fines de mantener la relación de intercambio entre oro y plata en el mercado en su valor legal (1884), constituye una de las propuestas más originales e inteligentes sobre un problema crucial en su época.

- El tema de los monopolios fue tratado en coherencia con el punto de vista teórico, como una situación en la cual el beneficio no era nulo incluso podía no cumplirse la uniformidad del precio (EEPP, Lección 41)y en la que, por tanto, no podían prescribirse las ventajas de la competencia. Diferenció entre monopolio natural y de interés social, analizándolos, respectivamente, en términos de los ferrocarriles - en los que había trabajado en su juventud- y de la propiedad intelectual. Sobre el primer tema se manifestó partidario no de que el Estado gestionara los ferrocarriles, sino de que fijara sus tarifas según el coste de producción, haciendo aportaciones a los métodos de cálculo de tarifas proporcionales y diferenciales $(1897 b$ ). En el segundo tema, del que se ocupó muy joven $(1859 \mathrm{~b})$, anticipó el argumento de Arrow sobre las ventajas para la sociedad de una protección temporal - patente- para un tipo de bien que, como los resultados de la investigación, no está protegido contra la apropiación por un sistema de competencia libre, por lo que su producción resulta desincentivada (1880).

- En el tema del mercado de trabajo sostuvo que el salario competitivo era el más acorde con el interés material, pero que el Estado debería intervenir en la regulación de las condiciones de trabajo y jornada, que eran causantes de dos tercios de las huelgas, con la consiguiente pérdida de riqueza social $(1867 c)$.

- Por último, sus frecuentes defensas de las cooperativas (1865) no implican colisión con el sistema competitivo, sino sólo una forma que Walras consideraba conveniente de organizar parte de la producción dentro de la competencia libre.

De este breve repaso se obtienen tres conclusiones. La primera es que todas las propuestas walrasianas en el campo de la economía aplicada se encuentran justificadas por los resultados teóricos de su análisis de equilibrio general competitivo, ya que cuando propone políticas no competitivas es porque se encuentra ausente, al menos, una de las condiciones bajo las que cabe 
concluir que la competencia es un sistema que maximiza la eficiencia, que es la proposición A). La segunda es que nuestro autor llevó a cabo numerosas aportaciones sólidamente fundamentadas a mucbos de los problemas más relevantes de su época. La tercera, que la economía pura y la aplicada se encuentran intimamente imbricadas en la obra de Walras, es decir, el corolario b).

\section{B) La coherencia lógica de la economía social con la pura.}

Dadas las posiciones políticas de Walras, ya comentadas en el epígrafe anterior, y la firmeza con que las defendió a lo largo de toda su vida, que tanto le alejan del estereotipo actual del teórico puro, cabría pensar que las preconcepciones ideológicas de Walras sesgaran su trabajo analítico ${ }^{21}$. Nada más lejos de la realidad.

Walras tenía dos tipos de preconcepciones. Una primera de carácter analítico: su creencia apriorística en las ventajas de la competencia libre desde la perspectiva del interés material. Una segunda de tipo ideológico: su creencia en que el sistema debería ser justo, en el preciso sentido de que hubiera igualdad real de oportunidades para todos y de que todos los ciudadanos fueran iguales no sólo ante la ley civil y política, sino también ante las leyes sociales y económicas $(1896 a, 1898 a$ ). Y fue precisamente su clara postura metodológica lo que le permitió separar los aspectos relativos a la eficiencia (economía política pura) de los referentes a la justicia (economía social). Por ello, la compatibilidad entre sus posiciones en ambos campos ha de buscarse, en caso de que exista, en la coherencia entre sus prescripciones sociales y el logro de la eficiencia.

Los dos grandes temas sobre los que Walras manifestó posiciones claras en el ámbito de la economía social fueron la intervención del Estado y, sobre todo, la teoría de la propiedad y la justicia.

Por lo que respecta a la intervención del Estado, su posición fue muy moderada. A la lista clásica añadió la regulación legal de los monopolios - tanto los naturales como los necesarios-, la reglamentación de las condiciones de trabajo y algunas propuestas puntuales, como, por ejemplo, la construcción de casas baratas municipales en Paris para mejorar las condiciones

${ }^{21}$ No es aquí lugar para dar una explicación detallada, pero el análisis de los trabajos que Walras no incluyó cuando decidió el contenido de $\operatorname{los} E E S$ y $\operatorname{los} E E P A$, así como las alteraciones de los que reeditó, es significativo de cómo la relación de causalidad va claramente desde la economía pura hacia la aplicada y social, y no en el sentido contrario (con la única excepción parcial de la teoría monetaria, que fue objeto de cambios sustanciales a lo largo de su vida, algunas de cuyas mejores páginas se encuentran en $\operatorname{los} E E P A$ y no en los EEPP). 
de vida de los obreros, que consideraba muy deficientes en las grandes concentraciones urbanas. Pero incluso esta última propuesta cabe pensar fue posteriormente abandonada, ya que desde su temprana formulación $(1860 b)$ no volvió a repetirse. Es de destacar que todas sus peticiones de intervención pública, en lo relativo a cambios del marco legal -en temas de cooperativas, organización monetaria, enseñanza superior, relaciones entre el Estado y la iglesia católica, derecho de familia, administración de la justicia y otros temas-, perseguían siempre una mayor flexibilidad institucional, el fortalecimiento de la competencia y la igualdad real de derechos. Un programa, en suma, claramente liberalizador en materia económica.

Lo que realmente se encuentra tras la generalizada opinión de que las posiciones de Walras en materia de economía social eran «mala metafísica» (Schumpeter), «posiciones increíbles» (Pareto) o, cuando menos, «carentes de interés» (Hicks) es su opinión de que "Las TIERRAS son, por derecho natural, propiedad del ESTADO" (1896 b, p. 218).

¿Es ésta una afirmación que echa por tierra las posiciones de Walras en materia de justicia, propiedad y fiscalidad? Me parece evidente que no, y ello por varias razones. En primer lugar - y aunque sea un argumento ad bominem no por ello deja de ser significativo-, fue una posición mantenida, entre otros muchos, por Gossen o Lloyd George, autores sobre los que nadie ha emitido un juicio descalificador global por ello. En segundo lugar, para Walras, la estricta posesión estatal de las tierras era poco relevante desde el punto de vista práctico, radicando su importancia en la implicación de que la única fuente de ingresos fiscales del Estado debía ser o las rentas de las tierras — si eran de propiedad pública - o la imposición sobre éstas — si se mantenían en manos privadas ${ }^{22}$. En tercer lugar, se puede estar en desacuerdo con la propiedad estatal de todas las tierras, tanto en sí misma como por la manera en que la formuló Walras - basta para ello con no creer en la existencia de un derecho natural-, pero esto no tiene por qué afectar a la valoración de sus implicaciones para la economía social, porque ésta dependerá de si su posición afecta o no al interés material, es decir, a la eficiencia.

En suma, la clave radica en determinar si es cierto que, aunque derivada de una discutible posición iusnaturalista, la propuesta fiscal de Walras ${ }^{23}$ per-

22 Esto es demostrable por el hecho de que Walras no tenía siquiera un esquema confiscatorio, sino que realizó precisos cálculos financieros para tratar de determinar bajo qué condiciones el Estado podría adquirir a los terratenientes sus tierras con el producto obtenido de las mismas (1881 b).

Sería más exacto decir de los Walras, ya que la posición fiscal de Léon proviene de su padre, Auguste $(1849,1850)$. Este no es, ni mucho menos, el único punto en que el hijo es, y se siente, deudor del padre (véanse EEPP, «Prólogo a la 4:" edición definitiva», y nn. 1 y 2 a la Lección 17 de la versión de Jaffé de 1954, pp. 122 y 432, respectivamente, de la versión española). 
mite un sector público financieramente sano que obtiene sus ingresos sin afectar a la eficiencia del sistema competitivo, aunque sí a la distribución de la riqueza. Si esto es cierto quedará demostrada la proposición B).

Desde el punto de vista analítico, es claro que todos los impuestos, con la sola excepción de los que gravan la tierra, alteran la eficiencia del sistema competitivo (v. gr., EEPP, Lección 42). Esto es así porque la tierra es un bien de capital cuya cantidad está dada y no es susceptible de modificación más que en cuantía despreciable (EEPP, Lección 17). Además, en una sociedad con inversión neta positiva, la renta de la tierra es creciente (EEPP, Lección 36). Todos éstos son resultados «ricardianos» ampliamente aceptados.

Un impuesto permanente sobre la renta de la tierra del $x$ por 100 equivale a un gravamen del $x$ por 100 sobre el valor de la tierra. Una vez fijado un impuesto sobre la renta de la tierra, su eliminación, o simple reducción del tipo, constituye un regalo de la sociedad a los terratenientes que hayan adquirido o heredado las tierras en la situación anterior; regalo de cuantía igual al $x$ por 100 del valor de las tierras y carente de justificación, sea cual sea el criterio de justicia socialmente aceptado.

Reuniendo todos estos argumentos, resulta que la posición de Walras, consistente en que el Estado perciba en su integridad la renta de la tierra, bien mediante un gravamen del 100 por 100 de la misma, bien mediante la propiedad pública de la tierra:

- no afecta al funcionamiento de la competencia libre;

- es flexible y suficiente por el crecimiento de la renta de la tierra en una sociedad progresiva;

- en su variante de propiedad estatal, es no discrecional porque evita la variación de los tipos sobre la renta de la tierra ${ }^{24}$;

en suma, una propuesta que hace el sistema fiscal desde el punto de vista de la economía política pura neutral respecto a la eficiencia, suficiente, flexible y no discrecional. Otra cuestión es que dicha propuesta afectara al derecho de herencia y proporcionara al Estado una autonomía que podía ser considerada peligrosa por las clases dominantes, pero esto es algo que entra en el campo de la valoración política de una propuesta que, desde el punto de vista puramente analítico, es irreprochable. Y ésta es la prueba de la proposición B).

* Cabe señalar incluso que, en coherencia con su posición sobre el tema de los ferrocarriles, en caso de propiedad pública estricta, Walras pensaba que el Estado no debí cultivar directamente las tierras, sino arrendárselas por un largo período a agricultores privados. 
De esta forma creo que la obra de Walras emerge, al cabo de un siglo, como un todo fuertemente trabado que incluye la elaboración formal más espectacular de la historia de la teoría económica, pero también un abanico de aportaciones más que notables en el campo de la economía aplicada y de la distribución de la riqueza que, se coincida o no con las posiciones ideológicas del autor, presentan una impecable coherencia lógica interna. Y queda la enseñanza de cómo el autor de la aportación más abstracta al análisis económico pudo usar las conclusiones formales de la misma para mantener posiciones reformadoras radicales en una sociedad barrida por conflictos sociales, producto de su incapacidad para dotar de contenido económico y social a los logros políticos de la Revolución Francesa.

\section{BIBLIOGRAFIA *}

ABREVIATURAS: CRP - Correspondencia (Jaffé, 1965).

EEPP - Elementos de economía politica pura (Walras, 1926).

EEPA - Estudios de economía politica aplicada (Walras, 1898 b).

EES-Estudios de economía social (Walras, $1896 \mathrm{c}$ ).

BARBER, W. J. (1967): A History of Economic Thought. Versión española de C. Solchaga y G. Barba con el título Historia del pensamiento económico (1971), Madrid, Alianza.

Blaug, M. (1966): Economic Theory in Retrospect, Londres, Heinemann. Versión española de M. Estartús con el título La teoria económica en retrospección (1968), Barcelona, Luis Miracle.

Bousquet, G. H. (1928): Viltredo Pareto, sa vie et son oeuvre, Paris, Payot.

BowleY, A. L. (1924): The Mathematical Groundwork of Economics, Oxford, Oxford University Press.

CASSEL, G. (1918): Theoretische Sozialökonomie. Versión inglesa con el título The Theory of Social Economy (1923). Versión española de M. Paredes con el título Economia Social Teórica (1960), Madrid, Aguilar.

EDGEWORT H, F. Y. (1889): "Review of the 2nd edition of the EEPP», Nature, vol. 40, núm. 1036, pp. 434436.

- (1925): Papers Relating to Political Economy (3 vols.), Londres, Macmillan.

Friedman, M. (1955): *Léon Walras and His Economic System», American Economic Review, vol. XLV, núm. 5, pp. 900-909.

GIDE, Ch., y RIST, Ch. (1909): Histoire des doctrines économiques depuis les physiocrates jusqu'a nous jours, París, Larose y Tenin. Versión española de la 4:" ed. francesa de C. Martínez Peñalver con el título Historia de las doctrinas económicas, Madrid, Instituto Editorial Reus (sin fecha).

* Siempre que se citen páginas de trabajos recopilados en los EES (L. Walras, 1896 c) o en los EEPA (L. Walras, 1898 b), serán las de Estos. Cuando se cita la versión eapañola de los trabajos, las páginas se refieren a la misma. Las obras citadas de Walras son las imprescindibles, pero una relación completa y comentada de toda la obra editada $e$ inédita puede encontrarse en Segura (1987, Apéndice II, pp. 71-102). Si no se indica otra cosa, las traducciones son de Julio Segura. 
Harrod, R. F. (1956): «Walras: A Re-appraisal», Economic Journal, vol. LXVI, número 262 , pp. 307.316 .

Hicks, J. R. (1934): «Léon Walras», Econometrica, núm. 2, pp. 338-348.

Hutch Inson, T. W. (1953): A Review of Economic Doctrines 1870-1929, Oxford, Clarendon Press. Versión española de E. Fuentes Quintana con el título Historia del Pensamiento económico $1870-1929$ (1967), Madrid, Gredos.

JAFFÉ, W. (1935): "Unpublished Papers and Letters of Leon Walras», Journal of Political Economy, vol. XLIII, núm. 2, pp. 187-207.

- (1954): Elements of Pure Economics, Londres, George Allen and Unwin. Versión española en Segura (1987).

- (1964): *New light on an Old Quarrel. Barone's Unpublished Review of Wicksteed's. Essay on the Coordination of the Laws of Distribution and Related Documents», en Cabiers Vilfredo Pareto, Ginebra, Droz, vol. III, pp. 61-102.

- (1965): (CRP) Correspondence of Léon Walras and Related Papers (3 vols.), Amsterdam, North-Holland.

- (1975): «Leon Walras, and economic adviser manquée», Economic Journal, 85, páginas 810-823.

- (1977): «The Normative Bias of the Walrasian Model: Walras versus Gossen*, Quaterly Journal of Economics, 91 (364), pp. 371-387.

- (1980): «Walras's Economics as Others See It», Journal of Economic Literature, vol. XVIII, pp. 528-549.

- (1981): «Another look at Léon Walras's theory of tâtonnement», History of Political Economy, 13: 2, pp. 313-336.

KuENNE, R. E. (1956): «The Architectonics of the Walrasian System», Kyklos, vol. IX, núm. 2, pp. 241-249.

- (1961): *The Walrasian Theory of Money: An Interpretation and a Reconstruction*, Metroeconomica, 13, pp. 94-105.

Marget, A. W. (1931): *Leon Walras and the "Cash Balance Approach" to the Problem of the Value of Money», Journal of Political Economy, vol. 39, núm. 5, pp. 569-600.

- (1935): «Monetary Aspects of the Walrasian System», Journal of Political Economy, vol. 43, núm. 2, pp. 145-186.

Morishima, M. (1977): Walras' Economics. A pure theory of capital and money, Cambridge University Press.

- (1980): «W. Jaffe on Leon Walras», Journal of Economic Literature, vol. XVIII, núm. 2, pp. 550-558.

Oules, F. (1950): L'école de Lausanne. Textes cboisis de L. Walras et V. Pareto, París, Dalloz.

Pantaleoni, M. (1908): *Leone Walras-autobiografia*, Giornale degli Economisti, volumen XXXVII, pp. 603-610.

Pareto, V. (1902): L'économie pure, editado por G. Bousquet (1955) en Metroeconomica, vol. 7 , núm. 1 , pp. $1-15$.

- (1916): Trattato di Sociologia Generale. Versión inglesa de A. Livingston con el título The mind and Society. A treatise on general sociology (1935), N. York, Harcourt, Brace.

PtGUY, Ch. (1897): «Un Economiste socialiste: M. Leon Walras», Revue Socialiste, vol. 25, núm. 146, pp. 174-186.

Rosa, G. de (1960): Vilfredo Pareto Lettere a Maffeo Pantaleoni, 3 vols., Roma, Banca Nazionale del Lavoro.

Rugina, A. N. (1982): «Leon Walras: The Pure Theorist versus the Social Reformerw, International Journal of Social Economics, vol. 9, núm. 3, pp. 1-40.

Szgura, J. (1974): «Nota autobiográfica», Anales de Economia, 3.' Epoca, núms. 21-22, pp. 17-35.

- (1987): Elementos de Economía Politica Pura (o teoria de la riqueza social), Madrid, Alianza. 
Schumpeter, J. A. (1951): «Marie Esprit Léon Walras», en Ten Great Economists from Marx to Keynes, N. York, Oxford University Press. Versión española de A. de Lucas con el título 10 grandes economistas, de Marx a Keynes (1967), Madrid, Alianza.

W (1954): History of Economic Analysis, Oxford University Press.

WLKER, D. A. (1970): *Leon Walras in the Light of His Correspondence and Related Papers*, Journal of Political Economy, 78, pp. 685-701.

- (1980): «Walras' Economics: A Pure Theory of Capital and Money» (recensión), History of Political Economy, 12: 1, pp. 131-135.

Walras, A. A. (1849 a): Théorie de la richesse sociale, ou résumé des principes fundamentaux de l'économie politique, París, Guillaumin.

- (1849 b): «De l'impôt sur le revenue» y «Essai sur l'impôt du revenue», inéditos, utilizados en L. Walras (1861 c).

- (1850): «De l'impôt sur le capital», inédito, utilizado en L. Walras (1861 c).

Walras, L. (1859 a): «Du sens esthétique; de l'art; et les opinions en matière d'art», ensayo no publicado hasta su inclusión en $(1867 b)$.

- (1859 b): *De la propriété intellectuelle. Position de la question 6conomique», Journal des Economistes, serie 2, vol. 24, núm. 12, pp. 392-407.

- $(1860$ a): «Des octrois. A propos de la loi Belge», La Presse, 12 y 22 de julio y 3 de agosto.

- (1860 b): «De la cherté des loyers a Paris», La Presse, 16 de octubre a 26 de noviembre.

- (1861 a): «Le nouveau régime commercial», texto inédito conservado en los Fonds Walras de la Universidad de Lausanne. Un resumen de Jaffé puede encontrarse en $C R P$, carta 70 , n. 3.

- (1861 b): «De l'élevation du taux d'éscompte», La Presse, 23 y 26 de enero.

- (1861 c): De l'impót dans le Canton de Vaud. Mémoire auquel un quatrième accesit a été décerné ensuite du concours ouvert par le Conseil d'Etat de Vaud sur les questions relatives d l'impót, Lausanne, Louis Vincent. Incluido, en parte, en los $E E S$, pp. 379-485.

- (1865): Associations populaires de consommation, de production et du crédit, París, Dentu.

- (1866 a): «Programme Economique et politique», Le Travail, 31 de julio.

- (1866 b): «Socialisme et liberalisme*, Le Travail, 31 de octubre y diciembre y 28 de febrero de 1867 . Incluido en los EES, pp. 3-21.

- (1867 a): aLes erreurs du système monetaire français», Le Travail, 31 de mayo.

- (1867 b): «La recherche de l'ideal social», Le Travail, 31 de octubre a 31 de marzo de 1868. Incluido en los EES bajo el epigrafe de «Thtorie Générale de la Société, pp. 25-171.

- (1867 c): *Discussion sur les coalitions et les grèves à la Société d'économie politique de Parisw, Le Travail, 30 de abril.

- (1872): «Système des phénomènes tconomiques», original no publicado de 10 conferencias dictadas en Ginebra en dicho año, conservado en los Fonds Walras de la Universidad de Lausanne. Un resumen de Jaffé puede consultarse en CRP, carta 198, n. 2, vol. I, pp. 293-296.

- (1874): «De l'influence de la communication des marchés sur la situation des populations agricoles*, Journal de la Société Vaudoise de l'Utilité Publique, núms. 105-106, pp. 103-119 y 121-135. Incluido en los EEPA, pp. 239-264.

- (1879 a): «De la culture et de l'enseignement des sciences morales et politiques», Bibliotbèque Universelle et Revue Suisse, Serie 3, vol. 3, núm. 7, pp. 6-32, y núm. 8, pp. 223-251.

- (1879 b): "Thérie mathématique du billet de banque*, Bulletin de la Société Vaudoise des Sciences Naturelles, Serie 2, vol. 16, núm. 83, pp. 553-592. Incluido en los EEPA, pp. 339-375.

- (1880): «De la propriété intellectuelle», Gazette de Lausanne, 10-12 de junio. Incluido en los $E E S$, pp. 247-263. 
- (1881 a): Théorie matbématique du bimétallisme, París, Guillaumin. Incorporado posteriormente como SS 286.289 de los EEPP.

- $(1881 b)$ : «Théorie mathématique du prix des terres et de leur rachat par l'Etat", Bulletin de la Société Vaudoise des Sciences Naturelles, Serie 2, vol. 17, núm. 85, pp. 189-284. Incluido en los EES, pp. 267-350 + 1 gráfico.

- (1884): «Monnaie d'or avec billon d'argent régulateur. Principes proposées à la Conference Monétaire pour la prorogation de l'Union Latinew, Revue de Droit International et de la Législation Comparke, vol. 16, núm. 6, pp. 575-588. Incluido en los EEPA, pp. 3-19.

- (1885 a): «D'un méthode de régularisation de la variation de valeur de la monnaie», Bulletin de la Société Vaudoise des Sciences Naturelles, Serie 2, vol. 21, núm. 92, pp. 71-92. Incluido en los $E E P A$, pp. 26-49.

- (1885 b): *Contribution à l'étude des variations des prix depuis la suspension de la frappe des écus d'argent» (en colaboración con A. Simon), Bulletin de la Société Vaudoise des Sciences Naturelles, Serie 2, vol. 21, núm. 92, pp. 93-103. Incluido en los EEPA, pp. 49-61 + 1 gráfico.

- (1889): «Opinions enoncées à la Commission d'experts chargés d'examiner le project de la loi féderale de mars 1881, dans les deux séances du 1 octobre 1889 ", texto inédito conservado en los Fonds Walras de la Universidad de Lausanne. Un resumen de Jaffé puede consultarse en CRP, carta 925, n. 12, vol. II, pp. 359-362.

- (1895): «Le pèril bimétalliste», Revue Socialiste, vol. 22, núm. 127, pp. 14-25. Incluido en los EEPA, pp. 175-190.

- (1896 a): «Méthode de conciliation ou de synthése», Revue Socialiste, vol. 23, núm. 136, pp. 385-406. Incluido en los EES, pp. 175-202.

- (1896 b): «Theorie de la propriété», Revue Socialiste, vol. 23, núm. 138, pp. 537.551. Incluido en los EES, pp. 205.239.

- (1896c): (EES) Etudes d'économie sociale (Théorie de la repartition de la richesse sociale), Lausanne, F. Rouge, y París, R. Pichon y R. Durand-Auzias, VIII + 488 pp. +3 gráficos. Edición definitiva, 1936, «par les soins de G. Leduc», mismos editores.

- (1896 d): «Le problème fiscal», Revue Socialiste, vol. 24, núm. 142, pp. 386-400. Incluido en los EES, pp. 445-485.

- (1897 a): «Thérie du libre échange», Revue d'Economie Politique, vol. 11, núm. 7, pp. 649-664. Incluido en los EEPA, pp. 286-304.

- (1897 b): «L'état et les chemins de fer», Revue de Droit Publique et de la Science Politique, vol. 7, núm. 3, pp. 417-436, y vol. 8, núm. 1, pp. 42-54. Incluido en los $E E P A$, pp. $193-232$.

- (1898 a): «Politique française: la prière du libre penseur», Gazette de Lausanne, 14 y 18 de julio. Incluido en $\operatorname{los} E E P A$, pp. 485-495.

- (1898 b): (EEPA) Etudes d'économie politique appliquée (Théorie de la ricbesse sociale), Lausanne, F. Rouge, y París, R. Pichon y R. Durand-Auzias, 495 pp. +10 gráficos. Edición definitiva, 1936, «par les soins de G. Leduc», mismos autores.

- (1926): (EEPP) Eléments d'économie politique pure (ou Théorie de la richesse sociale), 4." ed. definitiva, París, R. Pichon y R. Durand-Auzias, y Lausanne, F. Rouge, 491 pp. +4 láminas de gráficos (1." ed., 1874-79; 2." ed., 1889; 3." ed., 1896; 4." ed., 1900).

ZeUT r EN, F. (1942): Ôkonomisk Teori og Metode, Copenhaguen, Nyt Nordisk Forlag. Versión inglesa con el título Economic Theory and Metbod (1954), Massachusetts, Cambridge U. Press. Versión española de P. Mayor-de la inglesa- con el título Teoría y método en economia (1960), Madrid, Aguilar. 